\title{
Software for Optimizing International Water Resources Management
}

\author{
R. C. Peralta ${ }^{1}$ and $\mathrm{S} . \mathrm{Wu}^{2}$
}

${ }^{1}$ Water Dynamics Laboratory, Utah State University Research Foundation, and Biological and Irrigation Engineering Dept., USU, Logan, UT 84322-4105; PH (435) 797-2786; FAX (435) 797-1248; email:richard.peralta@usurf.usu.edu .

${ }^{2}$ Dept. of Water Resources, Modeling Support Branch, Bay-Delta Office, Sacramento, CA

\begin{abstract}
The Simulation/Optimization MOdeling System (SOMOS) has modules adapted for a range of international water resource management needs. The SOMOA module is best for field groundwater and conjunctive water management situations. It employs several analytical simulation models and several optimization methods to give appropriate optimal guidance for situations having sparse data. SOMOA requires understanding of the limitations of common analytical equations. It does not require experience in finite difference or element numerical modeling. SOMOS also has modules ideal for situations in which there is sufficient data for numerical modeling or aquifer and stream-aquifer systems. Emphasized here are SOMOA and its applications for common field-level water management problems. Sample situations include optimizing: minimizing required surface reservoir size for a period of low surface flows in a stream-aquifer system; conjunctive use for blending irrigation waters of different qualities; and artificial injection.
\end{abstract}

\section{Introduction}

Conjunctive use refers to coordinated use of groundwater and surface water resources. Conjunctive use is more complicated than using a single water resource. Using either resource can affect availability of the other in time and space. Often, conjunctive water managers must attempt to satisfy increasing water needs while reconciling conflicting water user goals and legal/regulatory or societal systems.

Attempting to assure sustainable crop production via conjunctive use involves water quantity and quality issues. Assuring a sustainable regional water supply often requires carefully managing both groundwater and surface water. It requires considering water 
quality and its affect on soil, crop and environment. It requires adapting to existing water laws and practices or possibly helping their change.

This paper describes a computer program useful for these tasks. The program contains simple simulation models (here abbreviated S models) based upon analytical equations. The program also contains a general purpose simulation/optimization (S/O) model useful for many physical and institutional systems. This flexible $\mathrm{S} / \mathrm{O}$ model permits using data of varied sophistication, including output from numerical finite difference or finite element simulation models used on site.

$\mathrm{S}$ and $\mathrm{S} / \mathrm{O}$ models differ in purpose and utility. An $\mathrm{S}$ model is designed to simulate how a physical system will respond to stimulus (groundwater extraction or injection, stream stage change, recharge and others). This is an important role because one cannot optimize management of a complicated system unless one can predict how the system will respond to management.

Even more than being able to predict how the physical system will respond, the manager wants to know how best to manage the system. He wants an optimal water management strategy. A 'strategy' is a set of spatially and temporally distributed water fluxes that can be directly managed by man. For example, a conjunctive use strategy might be a set of groundwater pumping and surface water diversion rates. A wastewater loading strategy might be a set of rates of discharges to a stream. A loading and conjunctive use strategy addresses both issues. A management strategy is developed to address a particular management 'scenario' (posed management problem).

An S/O model is designed to compute the best water management strategy for a userspecified management problem. A modeler can use a S/O model to calculate a better management strategy than he can usually develop using a normal simulation $(\mathrm{S})$ model. The difference in meaning between calculate and develop is significant.

Although normal simulation models have frequently been used to develop water management strategies, the best strategy developed in that way is usually not really optimal. It is only the best choice from among the strategies assumed and tested by the modeler. On the other hand, a strategy computed by a S/O model can be truly optimal-mathematically the best of an infinite number of possible strategies that will all satisfy the restrictions of a particular scenario. Personal experience has shown improvements of 10$40 \%$ in water management strategies between those developed using S/O models versus S models alone.

In essence, $\mathrm{S} / \mathrm{O}$ models solve mathematical optimization problems. An optimization problem consists of: variables; an objective function that includes some of the variables; constraint equations that include some of the variables, and bounds (upper and lower limits) on those variables. An S/O model computes the set of variable values that maximize or minimize the value of the objective function, while satisfying all constraint equations and bounds. 


\section{SOMOA S/O Model}

The presented SOMOA (Simulation/Optimization Model-Analytical) S/O model is derived from CONjunctive use Utility Software (CONJUS), (Peralta, 1999; Peralta and $\mathrm{Wu}, 1998)$. SOMOA can address physical systems ranging widely in complexity. It can solve optimization problems of the following types: linear programming, quadratic programming, goal programming, and mini-max and maxi-min goal programming.

SOMOA variables include pumping at wells, diversions from a stream, return flow to a stream, stream stage, line source recharge, field recharge, pumping at image wells (computed automatically), aquifer head, and stream depletion rate and cumulative resulting from pumping. SOMOA has linear and nonlinear objective functions that can employ pumping (extraction and injection), cumulative extraction, stream diversion, return flow, head, and stream depletion rate and cumulative volume. SOMOA permits the user to impose a range of constraints that the computed optimal pumping strategy must satisfy. The constraints represent physical, environmental, legal or social restrictions.

SOMOA modularity allows the user to easily pose an optimization problem for a simple homogeneous stream-aquifer system, and step through the optimization process (Figure 1). To calculate an optimal water management strategy, SOMOA first computes influence coefficients based upon analytical expressions (such as the Theis Equation). At that point, the user can optionally replace the SOMOA-derived coefficients with more accurate influence coefficients computed using field data or more sophisticated numerical $\mathrm{S}$ models.

SOMOA uses the selected influence coefficients to predict system response while calculating the mathematically best water use strategy for the user-specified problem. SOMOA-computed strategies are appropriate for many situations. SOMOA uses linearsystems theory adapted for nonlinear systems, to compute accurate pumping strategies even for heterogeneous and somewhat nonlinear systems.

SOMOA is written in Visual Basic. To simplify data organization and entry, and results post-processing, SOMOA and operates through Microsoft EXCEL. SOMOA provides tailored output plus the standard outputs of EXCEL, version 8 under Windows (Figure 2). 


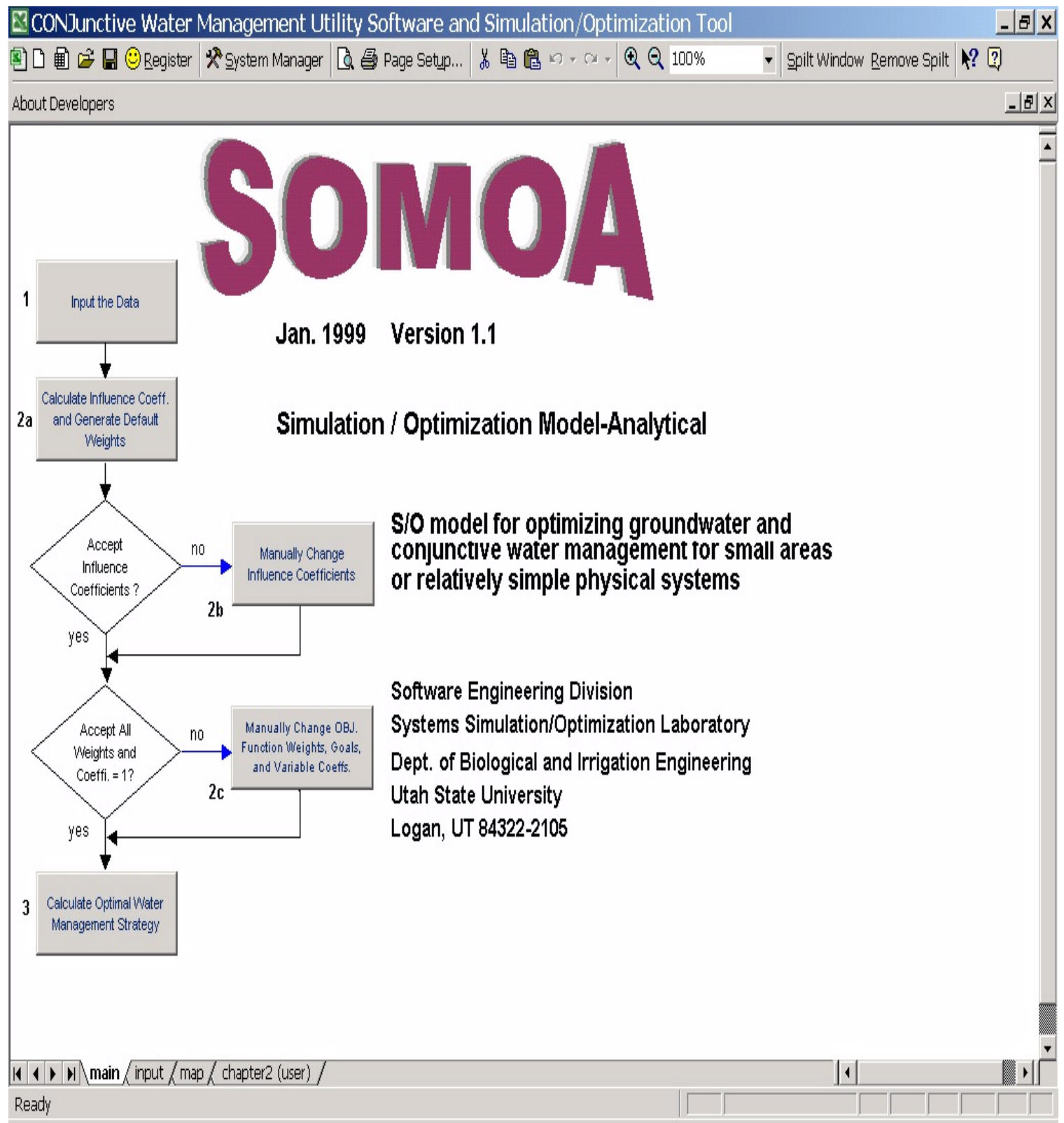

Figure 1. SOMOA Main Screen. 


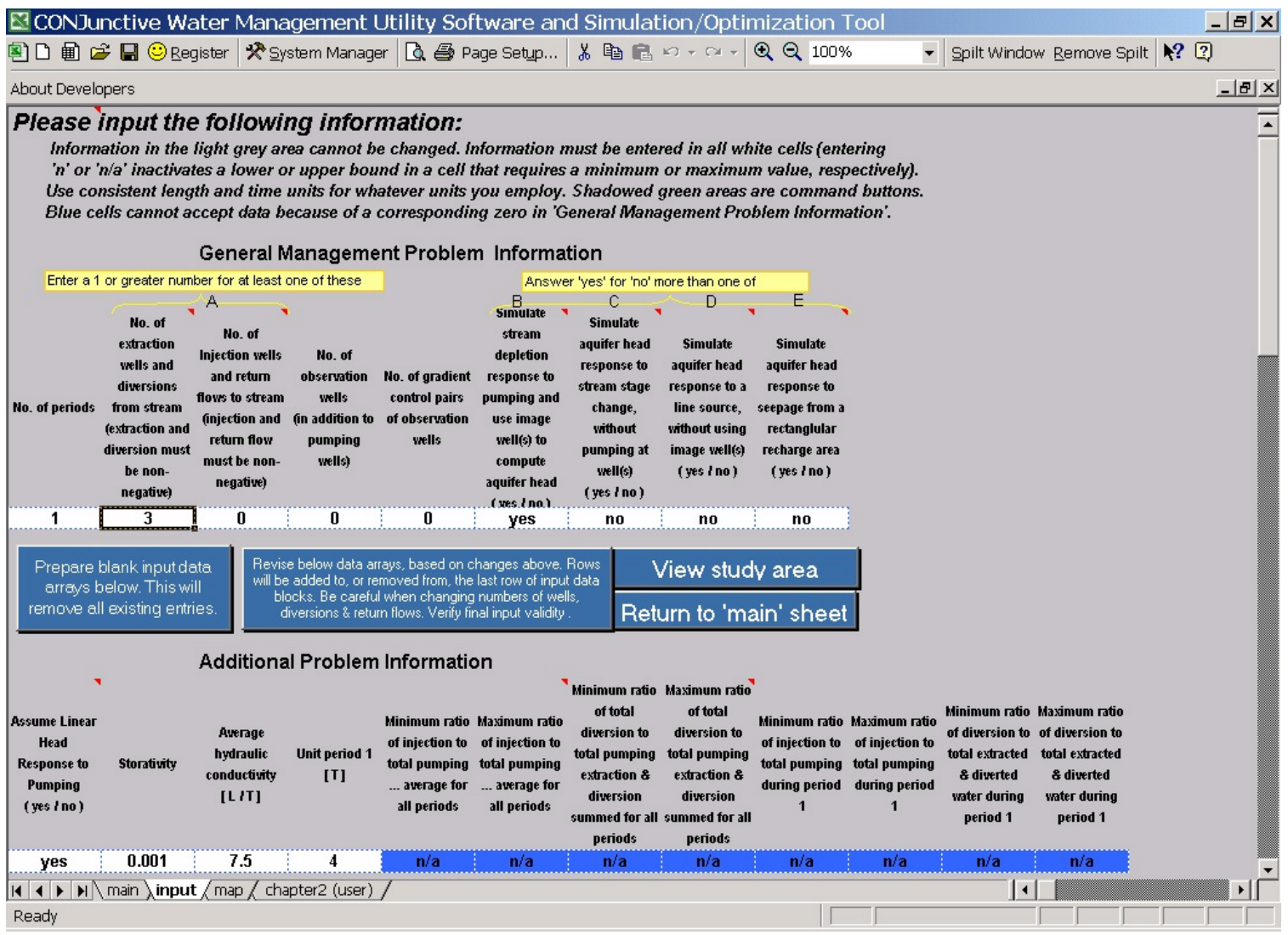

Figure 2. Sample Part of SOMOA Input Screen. 


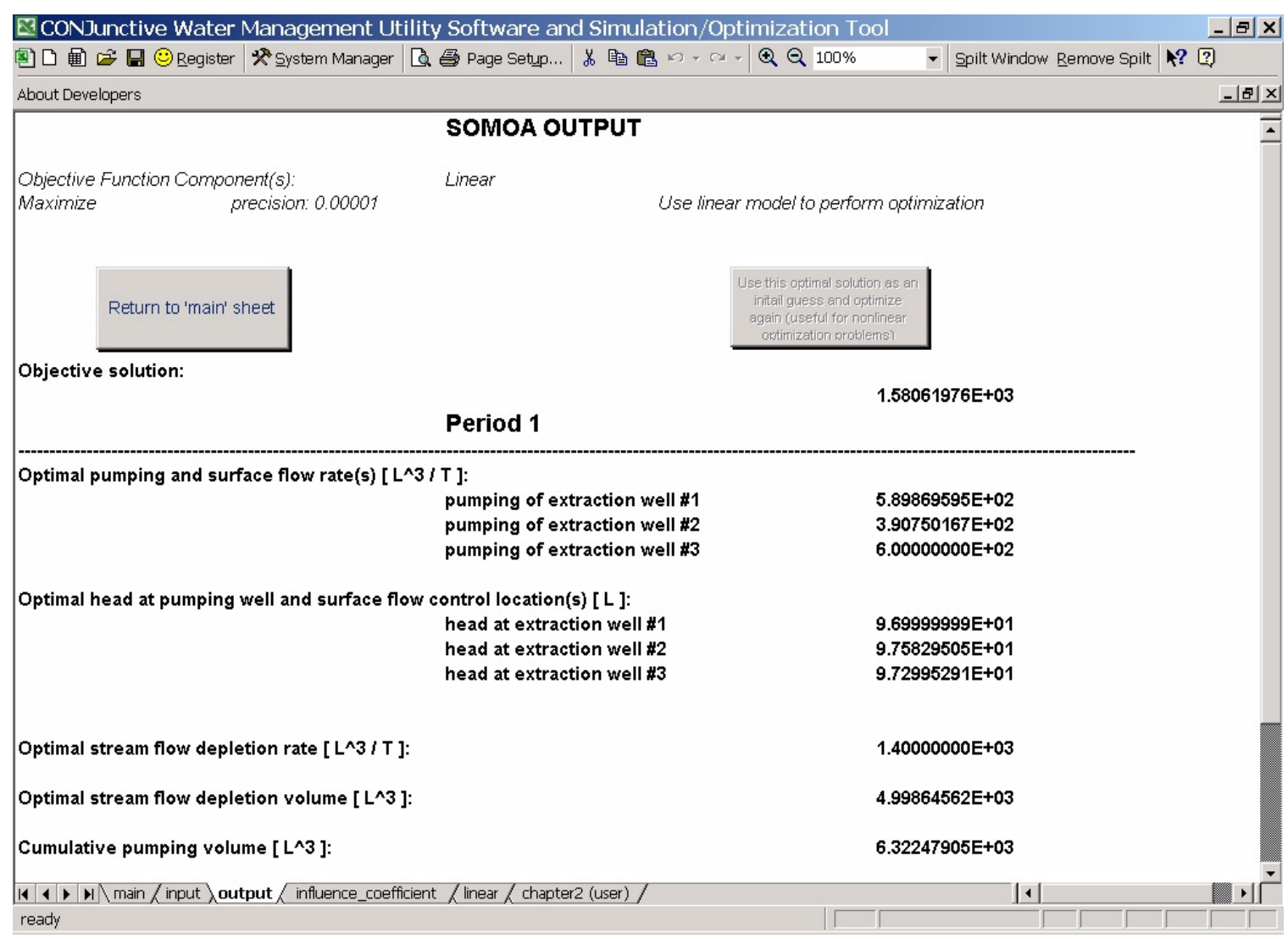

Figure 3. Sample Part of SOMOA Output Screen.

\section{Sample SOMOA Applications}

Example: Minimizing size of reservoir needed to provide adequate irrigation water while avoiding unacceptable stream depletion

Given. A farmer wants to irrigate using groundwater. His pumping well is 450 meters from a stream. The aquifer hydraulic conductivity is $20 \mathrm{~m} /$ day and storativity is 0.25 . The aquifer thickness is 30 meters and the well radius is $0.3048 \mathrm{~m}$. The initial water table is horizontal at 100 meters above sea level. The farmer needs 0.8 ha-meters of water per week for four weeks to satisfy his irrigation requirement, and is legally permitted to pump enough to satisfy his needs, as long as the stream depletion does not exceed 245 $\mathrm{m}^{3} \mathrm{~d}^{-1}$ at any time during the specified four-week groundwater pumping period. He does not want head just outside the well casing to drop below $97 \mathrm{~m}$.

The farmer asked an assisting irrigation engineer how much stream depletion would result from pumping steadily at the $0.8 \mathrm{ha}-\mathrm{m} / \mathrm{wk}\left(1142.8572 \mathrm{~m}^{3} \mathrm{~d}^{-1}\right)$ rate. The SOMOA answer is $251 \mathrm{~m}^{3} \mathrm{~d}^{-1}$ by the end of week 4, exceeding the legal upper limit. The engineer also used SOMOA to compute the maximum steady pumping rate that would not cause unacceptable stream depletion. The $1115.4 \mathrm{~m}^{3} \mathrm{~d}^{-1}$ rate would yield a total cumulative pumping of $31,232 \mathrm{~m}^{3}$ by the end of week 4 . 
The engineer then used SOMOA to minimize the total time-varying (transient) pumping that would satisfy both the $0.8 \mathrm{ha}-\mathrm{m} /$ wk lower bound and the $245 \mathrm{~m}^{3} \mathrm{~d}^{-1}$ upper bound. The computed optimal pumping strategy of 1751, 534, 1143 and $1170 \mathrm{~m}^{3} \mathrm{~d}^{-1}$ (for weeks 1-4) caused depletion rates of $25,127,181$ and $245 \mathrm{~m}^{3} \mathrm{~d}^{-1}$, respectively; and pumped only $32,192 \mathrm{~m}^{3}$ in total during the four week period (tight constraints were the $97 \mathrm{~m}$ head bound and the $245 \mathrm{~m}^{3} \mathrm{~d}^{-1}$ depletion bound). Unfortunately, by the end of week one this strategy would require a facility to store $4260 \mathrm{~m}^{3}$ of water $(12260-8000)$. This strategy does make use of the lag time between pumping and stream depletion, but probably does not do it as well as possible.

Wanted. Determine the smallest reservoir size needed to store the extra groundwater pumping such that the farmer can satisfy his water need without harming downstream water rights.

Solution. To identify the appropriate SOMOA objective function, it helps to restate the problem as follows. To have some water to store in the pond (or tank) for later use, one must pump more than the crop needs during some weeks. The more water one must store at any time, the larger the pond must be. One does not want to store any more water than absolutely necessary, while assuring that cumulative pumping is never less than cumulative water need (in order to always satisfy water need).

Cumulative pumping is the decision (management) variable. The restated management problem is to minimize the greatest weekly difference (exceedance) between cumulative pumping and cumulative water need; while using cumulative water need as the lower bound on cumulative pumping. Addressing this minimax (nonlinear) problem requires using: a goal programming objective, a lower bound on cumulative pumping, and upper bound on stream depletion. Because this is a very nonlinear problem, we ran the optimization multiple times, each beginning with a significantly different initial value for decision variables.

For this problem the optimal objective function values (optimal reservoir storage volumes) is $3843 \mathrm{~m}^{3}$. The tight constraint preventing further objective function improvement isthe $245 \mathrm{~m}^{3} \mathrm{~d}^{-1}$ stream depletion rate limit at the end of period 4. Optimal groundwater pumping rates for the four periods are $1692,5939,1140$, and $1145 \mathrm{~m}^{3} / \mathrm{day}$, respectively. Optimal pumping is lowest during period 2, because a unit pumping in period 2 will cause the greatest increase in stream depletion at the end of period 4.

\section{Example: Maximizing conjunctive use of extracted groundwater and diverted surface water while achieving appropriate salinity for irrigation}

Given. A farmer pumps from a groundwater well and diverts surface water from a stream passing through his property. He wants to maximize total water delivery to his crop during a two-month period, but must ensure that streamflow leaving his farm is sufficient for downstream users. Based upon the expected entering streamflow, he knows he should not deplete streamflow by rates exceeding $11,000 \mathrm{~m}^{3} \mathrm{~d}^{-1}\left(385,000 \mathrm{ft}^{3} \mathrm{~d}^{-1}\right)$ by the end day 30 , or by more than $11,500 \mathrm{~m}^{3} \mathrm{~d}^{-1}\left(402,500 \mathrm{ft}^{3} \mathrm{~d}^{-1}\right)$ by the end of day 60 . 
The maximum capacity of both well and diversion, individually, are $8,000 \mathrm{~m}^{3} \mathrm{~d}^{-1}$ $\left(280,000 \mathrm{ft}^{3} \mathrm{~d}^{-1}\right)$. The maximum water that can be reasonably utilized totals 13,000 and $16,000 \mathrm{~m}^{3} \mathrm{~d}^{-1}\left(455,000\right.$ and $\left.560,000 \mathrm{ft}^{3} \mathrm{~d}^{-1}\right)$, for the two respective months. Other project information includes:

- $\quad$ Stream runs from Northwest to Southeast $(100,1000)$ to $(800,0)$

- $\quad$ Diversion point is on the farm at $(200,858)$

- Groundwater well, of 0.2 m radius, is on the farm at $(450,850)$

- Conductivity is $80 \mathrm{md}^{-1}$

- $\quad$ Ground surface is at elevation $45 \mathrm{~m}$, and the groundwater surface is initially at equilibrium at elevation $40 \mathrm{~m}$. Saturated thickness is $40 \mathrm{~m}$.

- For sustainable production, (based on crop, soil, and salinity of the surface water and groundwater), at least $60 \%$ of the water used during period 1 must be from the stream, and at least $48 \%$ of the total water delivered during the two periods combined must be from the stream. The period 1 constraint protects seeds during germination. The total planning horizon constraint provides adequate leaching to prevent salinity buildup in the root zone.

Wanted. Determine the maximum conjunctive water use strategy, subject to constraints.

Solution. Employ SOMOA using Options A and B, one groundwater extraction well and one surface water diversion. Employ: two thirty-day stress periods, and an arbitrary unit pumping such as 8,000 . Also, use:

- $\quad$ upper limits of $8,000 \mathrm{~m}^{3} \mathrm{~d}^{-1}$ in each period on pumping and diversion;

- $\quad$ lower limit of 0.6 on period 1 \{diversion/(diversion + pumping extraction)

- $\quad$ lower limit of 0.48 on the above ratio for the total planning horizon,

- $\quad$ upper limits of 11,000 and $11,500 \mathrm{~m}^{3} \mathrm{~d}^{-1}$, respectively.

- $\quad$ upper limits of 13,000 and $16,000 \mathrm{~m}^{3} \mathrm{~d}^{-1}$ on pumping plus diversion.

Table 1 shows the computed optimal pumping strategy and state variable responses. Tight constraints are groundwater pumping in period 2, stream depletion in both periods, and the diversion ratio in period 1 and for the total season. Relaxing any tight constraint (for example, decreasing the required proportion of surface water) will cause total conjunctively provided water to increase.

Table 1. Optimal conjunctive use strategy and system responses.

\begin{tabular}{lccc} 
& Period 1 & Period 2 & Season Avg. \\
Groundwater pumping (GP), $\left[\mathrm{m}^{3} \mathrm{~d}^{-1}\right]$ & 4,774 & 8,000 & \\
Surface water diversion (SD), $\left[\mathrm{m}^{3} \mathrm{~d}^{-1}\right]$ & 7,001 & 4,573 & \\
Stream flow depletion, $\left[\mathrm{m}^{3} \mathrm{~d}^{-1}\right]$ & 11,000 & 11,500 & \\
GP + SD $\left[\mathrm{m}^{3} \mathrm{~d}^{-1}\right]$ & 11,774 & 12,573 & 12,174 \\
$\{\mathrm{SD} /(\mathrm{SD}+\mathrm{GP})\}$ & 0.6 & 0.36 & 0.48 \\
\hline
\end{tabular}




\section{Example: Maximizing artificial recharge in an unconfined aquifer.}

Given. Assume a $0.3 \mathrm{~m}$ radius well fully penetrates a $10 \mathrm{~m}$ thick unconfined aquifer having an initial equilibrium water level of $7 \mathrm{~m}$, a conductivity of $70 \mathrm{~m} / \mathrm{d}$ and a storativity of 0.2. This is similar to a field problem solved by Peralta, et al (1999).

Wanted. Compute the greatest rate that can be injected into the well without causing water levels to rise closer than $1 \mathrm{~m}$ to the ground surface after 60 days of pumping. (The ground surface is $10 \mathrm{~m}$ above the aquifer base.)

Solution. Use SOMOA with one stress period, one injection well, the unconfined aquifer option, and a $9 \mathrm{~m}$ upper limit on head at the injection well. When using the nonlinear aquifer option, SOMOA first computes head response via the Theis equation (which is perfect for linear aquifers), and then adjusts that to unconfined aquifer conditions using an approach by Jacob (1944) to prepare an influence coefficient. During optimization, SOMOA cycles until it converges to the maximum pumping rate that will not cause more than $2 \mathrm{~m}$ of head increase at the well. For this problem, using this process yields a maximum pumping rate of $931 \mathrm{~m}^{3} \mathrm{~d}^{-1}$.

In an unconfined aquifer, as injection mound height increases, transmissivity increases, and more water can flow away from the well. Therefore, an injection mound computed using the nonlinear option is lower than that computed using the linear option.

If a hydraulically connected stream were nearby and in equilibrium with the aquifer, the recharge mound would build more readily. Less pumping would cause a $2 \mathrm{~m}$ rise than if the stream were not present. During a low streamflow period one might extract water from the same well used for injection. To do this in SOMOA, site an extraction well at the same location as the injection well. Set pumping bounds so the extraction and injection wells cannot pump during periods 1 and 2, respectively. Use the nonlinear solver and an appropriate initial water level (initial saturated thickness) for the well.

\section{Other SOMOS Modules}

SOMOS (SSOL, 2003) has other modules that can optimize water and conjunctive water management for more complex hydrogeologic settings (Peralta, 2003). SOMO1 is ideal for water resources planning and management when primarily numerical flow models (primarily finite difference, but also finite element) are needed to simulate flow in the physical system. SOMO1 uses classical optimization algorithms (simplex, branch and bound, gradient search, outer approximation). SOMO1 has been used for scales ranging for local to aquifer-wide (Das, et al., 2004)

SOMO3 is ideal for groundwater contamination and water resources management when numerical flow and transport models are needed to simulate processes. SOMO3 also uses artificial networks as substitute simulators. SOMO3 employs heuristic optimizers such 
as genetic algorithm, simulated annealing, and taboo search. SOMO3 has been used for the largest and most complex groundwater contaminant plume problems yet addressed in the world (Peralta, et al., 2003). Included are miles-long plumes at Massachusetts Military Reservation and Blaine Naval Ammunition Depot, Nebraska.

\section{Summary and Conclusions}

Sometimes legal and institutional arrangements do not permit implementing mathematically optimal water management strategies. At the least, the presented tools can help identify water management enhancements that might be desirable, rules permitting. The tools can certainly speed evaluation of, and create optimal water management strategies for, a wide range of problems regardless of legal environment.

\section{References}

Das, R., Peralta, R. and Timani, B. 2004. Cache Valley: Optimizing Sustainable Water Use and Ecosystems while Considering Water Rights. In press for publication in Proceedings Arid Lands Symposium, EWRI World Congress, June 2004. 10 p.

Jacob, C. E. 1944. Notes on determining permeability by pumping tests under watertable conditions. U.S. Geological Survey mimeographed report.

Kalwij, I. M. and R. C. Peralta. 2004. Effect of optimization problem constraints on pump and treat designs for Tooele Army Depot. In press for publication in Proceedings, 2004 EWRI World Water Conference. 8 p.

Peralta, R.C. 1999. Conjunctive Use of Ground Water and Surface Waters for Sustainable Agricultural Production. FAO of the United Nations Consultancy Report. 158p.

Peralta, R. C. 2003. SOMOS Simulation/Optimization Modeling System. In Proceedings, MODFLOW and More 2003: Understanding through Modeling. International Groundwater Modeling Center, Golden, CO. p 819-823.

Peralta, R. C., Aly, A. H. and S. Wu. 1999. Examples of optimizing aquifer storage and recovery for Cache Valley. Part of proj. compl. rpt. (Eval. of Artificial Storage \& Recovery for Utah) sub. to Utah Div. of Water Res. by Kemblowski, Lachmar, Peralta. 5 p.

Peralta, R. C., *Kalwij, I. M. and S. *Wu. 2003. Practical simulation/optimization modeling for groundwater quality and quantity management. In Proc., MODFLOW and More 2003: Understanding through Modeling, Golden Colorado. IGWMC, p 784-788.

Peralta, R. C., and Wu, S. 1998. CONJUS user's manual. Systems Simulation / Optim. Lab., Dept. of Biological and Irrigation Eng., Utah State Univ., Logan, UT. 22 p.

Systems Simulation/Optimization Laboratory. 2003. SOMOS users manual. SS/OL, Department of Biological and Irrigation Engineering, Utah State University, Logan, Utah. 